\title{
Parallel interleukin 5 synthesis by eosinophils in duodenal and skin lesions of a patient with dermatitis herpetiformis
}

\author{
P Desreumaux, A Janin, E Delaporte, S Dubucquoi, F Piette, A Cortot, M Capron, \\ J F Colombel
}

\begin{abstract}
A 59 year old man is presented with a diagnosis of dermatitis herpetiformis. Duodenal and skin biopsy specimens from blisters of both recent and late onset were collected before treatment. Electron microscopy, immunohistochemistry, and in situ hybridisation were performed to analyse the presence of activated eosinophils and the local synthesis of interleukin 5 (IL5). Parallel state of eosinophil activation and IL5 synthesis was found in the duodenal mucosa with total flat mucosa and in skin vesicles of recent onset. It is suggested that duodenal and cutaneous eosinophils can synthesise IL5 and then participate in small bowel and skin lesions.
\end{abstract}

(Gut 1995; 37: 132-135)

Clinique des Maladies de l'Appareil Digestif, Hôpital Claude Huriez, Centre Hospitalier Régional Universitaire (CHRU) Lille, France $P$ Desreumaux A Cortot

J F Colombel

Laboratoire d'Anatomie et de Cytologie

Pathologiques, Hôpital Calmette, CHRU Lille, France

A Janin

S Dubucquoi

Service de

Dermatologie A,

Hôpital Claude

Huriez, CHRU Lille,

France

E Delaporte

F Piette

Centre d'Immunologie et Biologie Parasitaire, Institut Pasteur, Lille, France

M Capron

$S$ Dubucquoi

Correspondence to: Professor J F Colombel, Clinique des Maladies de l'Appareil Digestif et de la Nutrition, Hốpital Huriez CHRU Lille, 59037, Lille Cedex, France.

Accepted for publication 12 September 1994
Keywords: interleukin 5, dermatitis herpetiformis, eosinophils.

Dermatitis herpetiformis is a chronic polymorphous dermatitis characterised by intense itching, papulovesicular lesions with predilection site on elbows, knees, and buttocks, and deposition of IgA in the dermal papillae of the skin. Dermatitis herpetiformis is a gluten sensitive disease that occurs in patients with appropriate genetic background and sensitised $\mathrm{T}$ cells to gluten protein. ${ }^{1}$ Dermatitis herpetiformis is associated with a high frequency of the human leucocyte antigens (HLA) Al, B8, DR3, and DQw2. ${ }^{2}{ }^{3}$ Most patients have intestinal lesions similar to those of coeliac disease and respond to a gluten free diet. ${ }^{4}$

Morphometric studies have established that in duodenal mucosa of patients with coeliac disease the eosinophil population was considerably increased and returned towards normal values under gluten restriction. ${ }^{5} \mathrm{We}$ have recently shown that eosinophils were in an activated state and released cytotoxic proteins such as the major basic protein and eosinophil cationic protein, which could participate in mucosal damage. ${ }^{6}$ This activation could be mediated by synthesis of interleukin 5 (IL5) protein, which is the main factor for local eosinophil recruitment and activation. ${ }^{7}$
In dermatitis herpetiformis, biopsy specimens of skin lesions show characteristic neutrophilic abscesses in the dermal papillae. ${ }^{8}$ Presence of variable numbers of eosinophils have been reported but little is known about their role in blister formation. ${ }^{9}$

This prompted us to analyse the following parameters concomitantly in gut and skin lesions of a patient with dermatitis herpetiformis: presence of activated eosinophils, synthesis of basic proteins, and expression of IL5 messenger RNA and protein.

\section{Case report}

A 59 year old man was admitted with a 20 year history of recurrent vesiculous eruption and recent diarrhoea associated with a $10 \mathrm{~kg}$ weight loss. On admission the patient had a symmetrical itching eruption on the extensor areas of elbows, knees, ankles, and buttocks. Erythema and papulovesicles were associated with small bullae at various stages. The diagnosis of dermatitis herpetiformis was confirmed by histological examination and direct immunofluorescence. Multiple biopsy specimens of the duodenal mucosa showed a total flat mucosa and crypt hyperplasia related to a gluten sensitive enteropathy. Biological investigations suggested a proximal malabsorption of the small intestine: macrocytosis, low serum protide, albumin, vitamin B12, and folate concentrations associated with a reduced xylose absorption. After one month receiving a gluten free diet, the patient showed clinical, biological, and histological improvement: the diarrhoea had decreased and some of the skin lesions located on the upper body had dramatically improved. However, after the first month receiving a gluten free diet, eruption persisted on the ankles, knees, and buttocks. Thus, dapsone was added (200 $\mathrm{mg}$ per day) to accelerate the clinical benefit.

\section{Morphological studies}

Specimens were collected before any treatment by endoscopy from the terminal duodenum and by skin biopsies on blisters of both recent and late onset. They were immediately cut into two parts. One part was fixed in $1 \%$ glutaraldehyde in cacodylate buffer for one hour at $4^{\circ} \mathrm{C}$. 
Figure 1: Ultrastructural aspect of the inflammatory infiltrate in the duodenal mucosa of a patient with dermatitis herpetiformis. (A): Plasma cells (Pl) are intermingled with lymphocytes $(L)$ and eosinophils (Eo). Close cytoplasmic contacts are seen between plasma cells and eosinophils

(arrowheads). Some eosinophils have a cytoplasmic lysis with free extracellular granules (arrows). (B):

Ultrastructural aspect at a higher magnification of an eosinophil in the duodenal mucosa. Isolated changes in cytoplasmic granules with a disappearance of the central core (arrows).

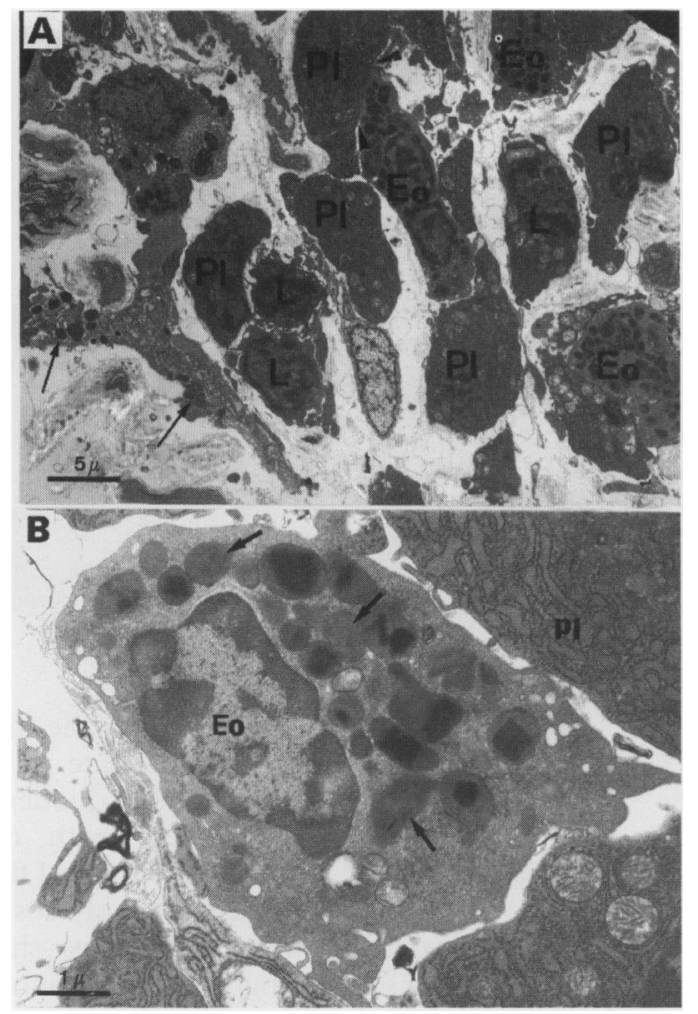

After dehydration, samples were embedded in Epon and further processed for ultrastructural studies. The other part was fixed in fresh $4 \%$ paraformaldehyde/phosphate buffered saline, and embedded in paraffin wax. Paraffin wax blocks were sectioned at $4 \mu \mathrm{m}$ for histochemical examination, in situ hybridisation, and immunolabelling. The results were obtained by systematic assessment of the number of positive cells per field at magnification 400 and a minimum of five fields per biopsy specimen were analysed.

Histochemical examination was performed with haematoxylin and eosin and May Grünwald Giemsa for assessing the skin and gut lesions, and the percentage of eosinophils in the inflammatory infiltrate. On the following paraffin wax sections, tissues were hybridised with the IL5 ${ }^{35} \mathrm{~S}$ labelled RNA probes. The complementary DNA for human IL5 was subcloned into the Blue Script vector by standard techniques. In brief, linearised plasmid was used as template for the synthesis in vitro of ${ }^{35} \mathrm{~S}$ labelled $\mathrm{RNA}$ probe (Amersham-France, Les Ullis, France) complementary to the cellular interleukin messenger RNA (antisense probe). RNA was also transcribed in the opposite direction and used as a negative control (sense probe). Antisense or sense probes $\left(4150 \mathrm{cpm} / \mathrm{mm}^{2}\right)$ were hybridised with duodenal and skin paraffin wax sections as previously described. ${ }^{10}$ To inhibit the non-specific binding of ${ }^{35} \mathrm{~S}$, tissues were acetylated in triethanolamine $0.1 \mathrm{M}$ for five minutes and then in acetic anhydride $0.25 \%$ triethanolamine for 10 minutes. Then to avoid non-specific binding to eosinophils, prehybridisation was carried out with a solution containing a non-radiolabelled S-UTP irrelevant probe for at least two hours at $42^{\circ} \mathrm{C}$, dithiothreitol was added to the hybridisation buffer, and RNAse $A$ was used for posthybridisation washings. ${ }^{11}$ After development of the emulsion, tissue sections were then counterstained with May Grünwald Giemsa for examination by light microscopy. On the following paraffin sections, indirect immunoenzymatic methods were used to detect the presence of eosinophil peroxidase, major basic protein, and IL5 proteins with the following antibodies: a monoclonal mouse antibody directed against eosinophil peroxidase (Oncogene Science, USA); BMK-13, a mouse monoclonal antibody that binds to major basic protein (TEBU, Le Perray en Yvelines, France), and a polyclonal rabbit antihuman IL5 (Genzyme, USA). These antibodies was respectively used at $1 / 100,1 / 50$, and $1 / 250$ and the binding was detected by means of streptavidin complex (LSAB2 Kit, alkaline phosphatase, Dako, USA). For immunohistochemistry, controls included: (a) omission of the first antibody and (b) substitution of the first antibody by an irrelevant antibody.

\section{Results}

\section{Duodenal mucosa}

Total flat mucosa with a dense inflammatory infiltrate comprising eosinophils at a mean percentage of $13 \%$ per field (range 10-15) were found on duodenal biopsy specimens. Ultrastructural analysis of eosinophils permitted characterisation of two kinds of changes: (a) cytoplasmic lysis with free extracellular granules (Fig 1A) and (b) isolated changes in cytoplasmic granules with an inverted density of the central cores (Fig 1B). Whether lytic or not, eosinophils were located around capillaries and had cytoplasmic contact with plasma cells (Fig 1).

In situ hybridisation with the IL5 antisense probe resulted in a staining of 10 to $15 \%$ of the inflammatory cells per field at magnification 400. Controls with the IL5 sense probe were negative. Similar to in situ hybridisation, immunohistochemistry with anti-IL5 antibody resulted in a staining of 10 to $15 \%$ of the inflammatory cells confirming the translation of the mRNA (Fig 2A). At higher magnification $(\times 1000)$, most stained cells had the morphological characteristics of eosinophils (Fig 2B).

Immunohistochemistry with anti-major basic protein antibody showed a staining on 6 to $8 \%$ of the inflammatory cells when 12 to $15 \%$ of them were stained with anti-eosinophil peroxidase antibody. Then, the stained cells pattern was similar by immunohistochemistry for eosinophil peroxidase and IL5. Controls without the first antibody or with an irrelevant antibody were negative.

\section{Skin lesions}

Skin biopsy specimens showed a subepidermal blister surrounded by dermal neutrophils in skin lesions of recent onset. Eosinophils were present ( $5 \%$ of the inflammatory infiltrate) in lesions of recent onset but rare in late lesions. At ultrastructural study, eosinophils were not 
Figure 2: Duodenum: paraffin wax section of total flat mucosa. (A): Positive IL5 immunostaining of the inflammatory cells of the lamina propria on paraffin wax sections (indirect immunophosphatase $\times 400)$. (B): At a higher magnification, most of the positively labelled cells have bilobated nuclei (indirect immunophosphatase $\times 1000$ ).

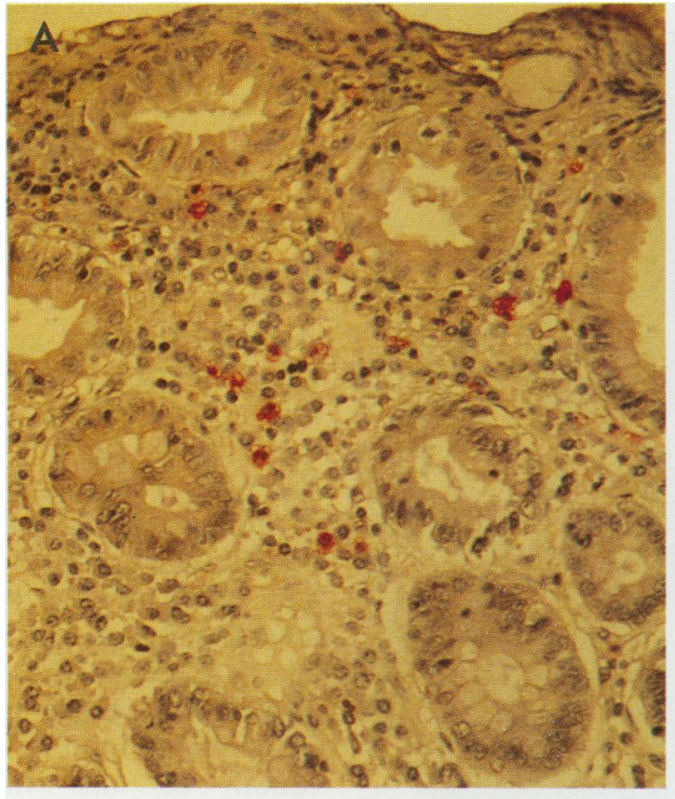

lytic but had granule changes similar to those seen in duodenal samples.

Positive in situ hybridisation signals were seen in recent skin lesions with the IIL5 antisense probe and not with the control sense probe. No in situ hybridisation staining was obtained in the skin lesions of late onset. Similar to the duodenal mucosa, immunohistochemistry with anti-IL5 antibody showed a staining of $5 \%$ of the inflammatory cells per field at a magnification 400. Most IL5 stained cells had polylobated nucleus at a higher magnification (Fig 3A) and a similar label intensity was obtained with anti-major basic protein and antieosinophil peroxidase antibody on the serial sections suggesting that these cells were probably eosinophils (Fig 3B). Controls for immunohistochemistry without the first antibody or with an irrelevant antibody were negative.

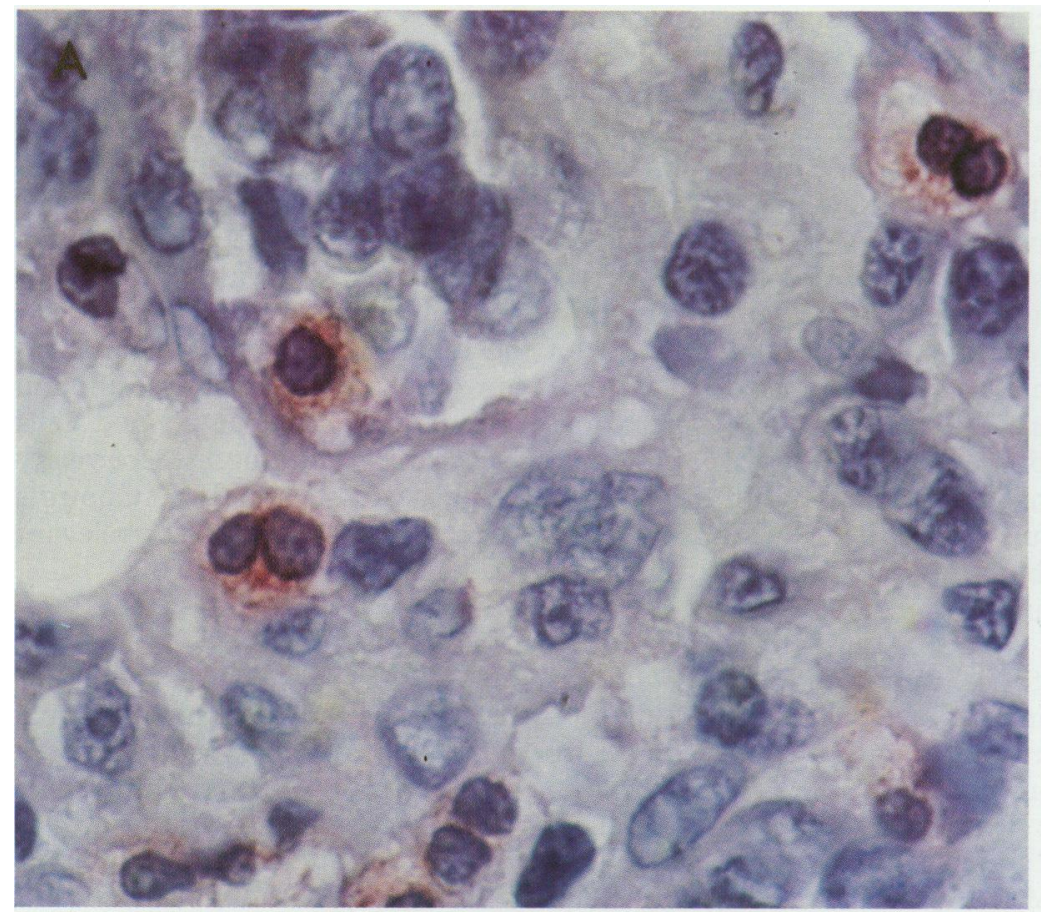

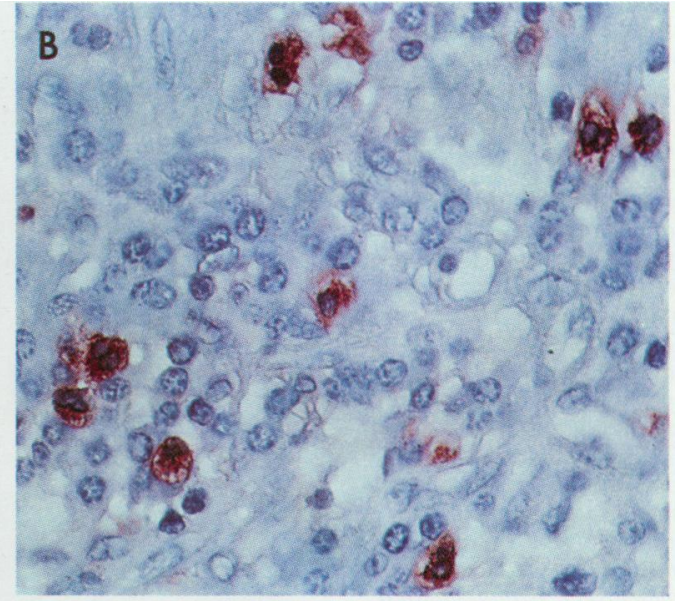

Discussion

We report for the first time a similar and concomitant state of activation and IL5 synthesis by both duodenal and skin eosinophils in a patient with dermatitis herpetiformis associated with total flat mucosa.

In this patient, eosinophils were numerous and activated as shown by ultrastructural changes and immunohistochemical studies in the duodenal mucosa and skin lesions of recent onset. Electron microscopy displayed ultrastructural signs of eosinophil activation such as extracellular granules or an inverted density of the central core, or both. Immunohistochemistry showed an extracellular release and tissue deposition of eosinophil peroxidase and major basic protein. These cytotoxic proteins are specific markers of eosinophils and their release in the tissue are indicators of activation. ${ }^{12}$ In the gut, these ultrastructural and immunohistochemical findings parallel the results previously seen in the duodenal mucosa of patients with coeliac disease. ${ }^{6}$ In skin lesions of patients with dermatitis herpetiformis, many reports have emphasised the role of neutrophils in the pathogenesis of blister formation. ${ }^{13}$ Eosinophils are present in the cellular infiltrate, however, and could participate in bullous formation as high blister eosinophil cationic protein concentrations have also been

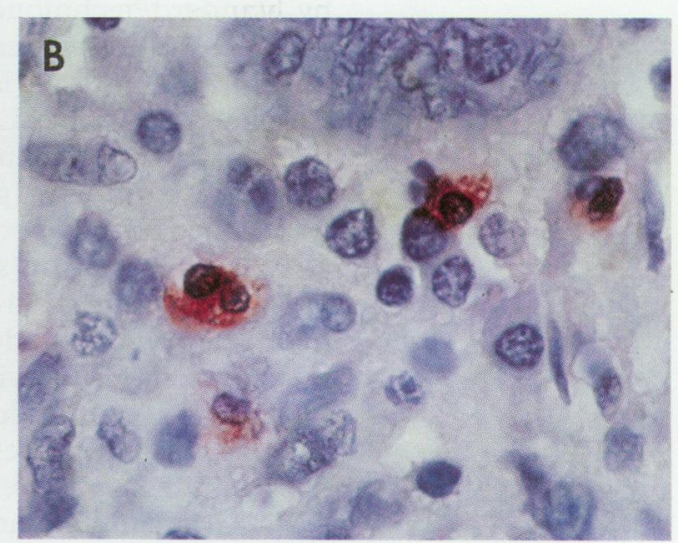

Figure 3: Skin biopsy of a blister of recent onset. (A): Positive IL5 immunostaining in the superficial dermis on serial paraffin wax sections (indirect immunophosphatase $\times 1000)$. Most labelled cells have a bilobated nucleus. (B). Positive eosinophil peroxidase immunostaining of cells with bilobated nucleus on paraffin wax sections (indirect immunophosphatase $\times 1000$ ). 
reported. ${ }^{14}$ Thus it is probable that in dermatitis herpetiformis, mucosal intestinal damage and skin blister could be partly related to the toxic effects of activated eosinophils.

Another parallel finding in the duodenal mucosa and skin lesions of this patient was that activated eosinophils expressed IL5 mRNA and synthesised the related protein. Expression of IL5 mRNA by eosinophils has been shown in jejunal mucosa of patients with coeliac disease. ${ }^{7}$ IL5 exerts a wide range of effects on eosinophils: it supports the proliferation and terminal differentiation of eosinophilic precursors $^{15}$ as well as the prolonged survival of eosinophils in vitro. ${ }^{16}$ It is also a selective chemotactic agent for eosinophils and a potent activator, leading to release of specific cationic proteins like major basic protein or eosinophil peroxidase. ${ }^{17}$ The local synthesis of IL5 in skin and duodenum of this patient with dermatitis herpetiformis might contribute to the proliferation, adhesion, and activation of eosinophils.

Similar to coeliac disease, where eosinophils and IgA plasma cells are closely associated in the mucosa, ${ }^{6}$ we found a structural relation between eosinophils and plasmocytes in duodenal mucosa of the patient with dermatitis herpetiformis. Such an association was not studied in the skin but dermatitis herpetiformis is characterised by deposition of granular IgA in dermal papillae. ${ }^{8}$ IgA is the most abundant Ig isotype in secretions and can bind to eosinophils by Fc $\alpha$ receptors. ${ }^{18} 19$ Recently, Dubucquoi et al have shown that IL5 was identified in eosinophilic granules mainly after stimulation with IgA immune complexes. ${ }^{20}$ In view of these results, it can be hypothesised that duodenal and skin eosinophils could secrete IL5 after activation by IgA. Therefore, autocrine effects of IL 5 can also be discussed, as IL5 membrane receptors have been described, specially expressed on tissue eosinophils. ${ }^{21}$

Gut and skin are important immune systems. Gut comprised specialised lymphoid structures namely the mucosa associated lymphoid tissue. A well defined cell traffic regulated in part by expression of adhesion molecules has been described between the gut and different tissues of the body. ${ }^{22}$ As infiltrating lymphocytes in the skin and the duodenal mucosa of patients with dermatitis herpetiformis expressed some identical lymphocyte homing receptors, ${ }^{23}$ we hypothesised that intestinal cells triggered by gluten could enter the skin as a result of the homing process. The granular deposits of IgA in the skin could then activate the effector cells such as eosinophils, which can then synthesise IL5 and cytotoxic proteins. The persistence of cutaneous IgA deposits in patients with dermatitis herpetiformis receiving a gluten free $\operatorname{diet}^{24}$ could explain the slow disappearance of skin lesions compared with the intestinal lesions.

Dermatitis herpetiformis is a blistering skin disease associated with a gluten sensitive enteropathy. Many patients with dermatitis herpetiformis have both intestinal and cutaneous manifestations, which can be controlled by a gluten free diet. ${ }^{4}$ This suggests that mucosal immune response is important in the pathogenesis of dermatitis herpetiformis and that skin and intestinal mucosa share some immunological identities. The concomitant state of activation and IL5 synthesis by duodenum and skin eosinophils represent a common pathophysiological abnormality that reinforces this hypothesis.

This work was supported by the Centre Hospitalier Régional Universitaire Lille (contract 93-02) and the Réseau Clinique INSERM No 492003 .

1 Marsh MN, Ensari A, Morgan S. Evidence that gluten sensitivity is an immunologic disease. Curr Opin Gastroenterol 1993; 9: 994-1000.

2 Marsh MN. Gluten, major histocompatibility complex, and the small intestine: a molecular and immunobiologic approach to the spectrum of gluten-sensitivity ('Celiac Sprue'). Gastroenterology 1992; 102: 330-54.

3 Reunal T, Mäki M. Dermatitis herpetiformis: a genetic disease. Eur f Dermatol 1993; 3: 519-26.

4 Katz SI. Treatment: drugs and diet. Dermatitis herpetiformis: the skin and the gut. Ann Intern Med 1980; 93: 857-74.

5 Marsh $M N$, Hinde J. Inflammatory component of celiac sprue mucosa. 1. Mast cells, basophils, and eosinophils. Gastroenterology 1985; 89: 92-101.

6 Colombel JF, Torpier G, Janin A, Klein O, Cortot A, Capron A. Activated eosinophils in adult coeliac disease: evidence for a local release of major basic protein. Gut 1992; 33: 1190-4.

7 Desreumaux P, Janin A, Colombel JF, Prin L, Plumas J Emilie D, et al. Interleukin 5 messenger RNA expression by eosinophils in the intestinal mucosa of patients with by eosinophils in the intestinal mucosa of patic

8 Katz SI. Dermatitis herpetiformis: clinical, histologic, therapeutic and laboratory clues. Int $\mathcal{F}$ Dermatol 1978; 17 529-35.

9 Blenkinsopp WK, Haffenden GP, Fry L, Leonard JN Histology of linear IgA disease, dermatitis herpetiformis, and bullous pemphigoid. $A m \mathcal{F}$ Dermatopathol 1983; 5: 547-54.

10 Peuchmaur M, Emilie D, Crevon MC, Solal-Celigny P, Maillot MC, Lemaigre G, et al. IL-2 mRNA expression in Tac-positive malignant lymphomas. Am f Pathol 1990; 136: 383-90.

11 Wong DTW, Weller PF, Galli SJ, Elovic A, Rand $\mathrm{H}$ Gallagher GT, et al. Human eosinophils express transform ing growth factor alpha. $₹$ Exp Med 1990; 172: 673-81.

12 Venge P. Immunopharmacology of eosinophils. 4. Human eosinophil granule proteins: structure, function and release. London: Academic Press, 1993: 43-55.

13 Graebber M, Baker BS, Garioch J, Valdimarsson H, Leonard JN, Fry L. The role of cytokines in the generation of skin lesions in dermatitis herpetiformis. $\mathrm{Br} f$ Dermatol 1993; 129: 530-2.

14 Cox NH, Cooper PN, Venge P, Friedmann PS. Eosinophil cationic protein in bullous pemphigoid, dermatitis herpetiformis and other blistering disorders. Eur $\mathcal{F}$ Dermatol 1993; 3: 294-8.

15 Yamaguchi Y, Suda T, Suda J, Eguchi M, Miura Y, Harada $\mathrm{N}$, et al. Purified interleukin 5 supports the terminal differentiation and proliferation of murine eosinophilic precursors. $\mathcal{F}$ Exp Med 1988; 167: 43-56.

16 Yamaguchi Y, Hayashi Y, Miura Y, Kasahara T, Kitamura S, Torisu M, et al. Highly purified murine interleukin-5 S, Torisu M, et al. Highly purified murine interleukin-5 (IL-5) stimulates eosinophil function and p

17 Lopez AF, Sanderson CJ, Gamble JR, Campbell HD Young IG, Vadas MA. Recombinant human interleukin 5 is a selective activator of human eosinophil function. $\mathcal{f} \operatorname{Exp}$ Med 1988; 167: 219-24.

18 Monteiro RC, Hostoffer RW, Cooper MD, Bonner JR Gartland GL, Kubagawa $H$. Definition of immunoglobulin A receptors on eosinophils and their enhanced expression in allergic individuals. $\mathcal{F}$ Clin Invest 1993; 92: 1681-5.

19 Capron M, Tomassini M, Van der Vorst E, Kusnierz P, Papin JP, Capron A. Existence et fonctions d'un récepteur paut l'IgA sur les éosinophiles humains. $C R A c a d S c i$ 1988; 307: 397-402.

20 Dubucquoi S, Desreumaux P, Janin A, Klein O, Goldman $M$, Tavernier $\mathrm{J}$, et al. Interleukin 5 synthesis by eosinophils: association with granules and immunoglobulin-dependent secretion. F Exp Med 1994; 179: 703-8.

21 Chihara J, Plumas J, Gruart V, Tavernier J, Prin L, Capron A, et al. Characterization of a receptor for interleukin 5 on human eosinophils: variable expression and induction by granulocyte-macrophage colony-stimulating factor. $\mathcal{f} E x_{p}$ Med 1990; 172: 1347-51.

22 Salmi M, Jalkanen S. Regulation of lymphocyte traffic to mucosa-associated lymphatic tissues. Gastroenterol Clin North Am 1991; 20: 495-510.

23 Jalkanen S, Saari S, Kalimo H, Lammintausta K, Vainio E, Leino $\mathrm{R}$, et al. Lymphocyte migration into the skin: the role of lymphocyte homing receptor (CD44) and endothelial cell antigen (HECA-452). $\mathcal{F}$ Invest Dermatol 1990; 94: 786-92.

24 Ljunghall $\mathrm{K}$, Tjernlund U. Dermatitis herpetiformis: effect of gluten-restricted and gluten-free diet on dapsone requirement and on IgA and C3 deposits in uninvolved skin. Acta Derm Venereol 1983; 63: 129-36. 